\title{
Um breve balanço da pesquisa sobre violência escolar no Brasil
}

Marilia Pontes Sposito

UniversidadedeSãoPaulo

Resumo

0 artigo realiza balanço da pesquisa so breasrelaçõesen trevi olência e escola no Brasil, após 1980. Examina os raros diagnósticos quantitativos em torno do tema e a produção discente (dissertações e teses) na pós- graduação em Educação, no mesmo período. Apesar de ainda ser incipiente, a produção já traça um quadro importante do fenômeno no Brasil, mostrando as principais modalidades: ações contra o patrimônio - depredações, pichações - e formas de agressão interpessoal, sobretudo entre os próprios alunos.

Durante esse período a violência em meio esco lartan to foi examinada como decorrência de um conjunto significativo de prá ticas escolares inadequadas, quanto foi investigada como um dos aspectos que caracterizam a violência na sociedade contem po rânea. Nesseúl ti mo en fo que, partedostrabalhospesquisou a dinâmica de funcio namen to deescolassituadasemáreas sob a influência do tráfico de drogas ou do crime organizado e um pequeno conjunto buscou entender o comportamento dos alunos como uma forma de sociabilidade marcada pelas agressões e pequenos delitos, caracterizada como incivilidade, que se origina na crise do processo civilizatório da sociedade contemporânea.

Palavras-chave

Violência escolar - Pesquisas - Brasil. 


\title{
A brief survey of the research on school violence in Brazil
}

Marilia Pontes Sposito

Universidade de São Paulo

\begin{abstract}
The article surveys the research on the relationships between violence and school in Brazil after 1980. It examines the rare quantitative diagnostics about the issue, and the theses and dissertations produced in graduate programs in Education in the same period. A though still incipient those studies al ready draw an important picture of the phenomenon in Brazil, displaying the leading modes of violence: acts against property - vandalism, graffiti - and interpersonal aggression, mainly among the pupils.

During this period, violence at school has been examined both as a consequence of a significant set of inadequate school practices, and as one of the aspects that characterizes the violence of contemporary society. Under the latter viewpoint, some of the works have investigated the dynamics of the workings of schools located in areas influenced by drug traffic or organized crime, and a small subset tried to understand the behavior of pupils as a socialization marked by aggressions and petty crime, characterized as incivility originated in the crisis of civilizatory process of contemporary society.
\end{abstract}

Keyw ords

School violence- Educacional research - Brazil.

\section{Correspondence:}

Marilia Pontes Sposito

Fa cul da de de Edu ca ção - USP

Av. da Uni versi da de, 308 - Blo-

co A - sala 223

05508-900 - São Paulo - SP

e-mail: sposito@usp.br 
Este artigo ${ }^{1}$ realiza um primeiro balanço da pesquisa sobre as relações entre violência e escola no Brasil. Embo ra não possa oferecerum quadro exaustivo da produção de conhecimento, os trabalhos analisados representam aproximações diferentes sobre 0 fenômeno e oferecem informações importantes, capazes de caracterizar a vio lên ciaesco larno Brasil, so bretudo nos centros urbanos. Indicam, ao mesmo tempo, algumas lacunas e a necessidade de no vas investigações para que essa área de estudos se consolide.

Há um primeiro grupo de investigações que exprime tentativas de diagnósticos em âmbito local ou mais geral que, mesmo não oferecendo um quadro preciso sobre a dimensão, a diversidade e a magnitude da questão, apresentam informações importantes sobre a ocorrência desses episódios em várias cidades brasileiras. Essas investigações são empreendidas, sobretudo, por organismos públicos da educação,associações de classe e, de modo menos freqüente, por institutos privados de pesquisa ou por pesquisadores ligados às universidades. Nem sempre, diante das condições materiais em que se realizam ou dasprecárias definições de amostragem, permitem generalizações confiáveis. Não buscam criar um quadro teórico interpretativo sobre o fenômeno, mas oferecem indicações importantes tanto sob ponto de vista do estímulo a novas pesquisas como do quadro em que ocorrem os principais eventos observados nas relações entre a escola e a violência.

0 segundo grupo reúne o conjunto de trabalhos realizados nos estudos da pós-graduação e por algumas equipes de investigadores ligados às universidades. A pesquisa nas Ciências Sociais vem incorporando nesses últimos vinte anos o tema da violência e seus vários desdobramentos, tornando-se um campo promissor de interesse dos investigadores. Mesmo assim, um levantamento empreendido junto a várias instituições do país, não registrou nenhum estudo sobre violência escolar. $\mathrm{Na}$ área da Educação, essatemática mui to tardiamente co meça aser objeto de preo cu paçãona pós-graduação, refletindo-se, assim, na produção discente. ${ }^{2}$

Apesar do intenso debate público em torno da violência e de sua relação com os segmentos juvenis quer como protagonistas, quer como vítimas, as equipes de pesquisadores demoram a assimilar no conjunto de seus interesses 0 tema das relações entre violência e escola. Verifica-se, também, nesses últimos vinte anos, a inexistên ciadeum programanacional de investigações sobre violência escolar proposto pelo Poder Público através de suas agências de fomento à pesquisa. ${ }^{3} \mathrm{No}$ en tanto, se é preciso reconhecer a fraca indução porpartedosorganis mos pú blicos, não épossível desconsiderar, também, que 0 interesse acadêmico pela questão ain daébastantein cipiente. ${ }^{4}$

Por outro lado, qualquer tentativa de balanço da produção, como afirmam Débarbieux e Montoya (1998), implica também reconhecer que a realização dos estudos se dá em um espaço social de constituição do tema da violência escolar como objeto legítimo de debate no in teri orda esfera pú blicaedeaten-

1. Texto apresentado no Congresso Internacional sobre Violência em meio Escolar, Paris, 2001.

2. Somando-se o conjunto de teses e dissertações produzidas entre 1980 e 1998 em toda a pós-graduação em Educação no Brasil verificamos que, de um total de 8.667 trabalhos, somente nove investigaram o tema da violência escolar (Sposito, 2000). Em Ciências Sociais, considerada a produção de onze Programas de pós-graduação (compreendendo centros de intensa produção como Rio de) aneiro, São Paulo, Minas Gerais, Santa Catarina e Rio Grande do Sul) verifica-se que nesse mesmo período nenhuma dissertação ou tese de doutorado foi defendida sobre o tema em relação a um total de 2.495 títulos objetos de exame (Sposito, 1999).

3. A principal agência de pesquisas do estado de São Paulo, FAPESP, uma das mais sólidas no país, lançou um programa especial de pesquisas sobre a escola pública no início de 1996. Até fevereiro de 2001 foram contemplados 65 projetos de um total de 279 inscrições. Nenhuma das propostas encaminhadas teve como tema a violência escolar.

4. Estudos de natureza histórica sobre o tema da violência e indisciplina nas escolas ainda são necessários. 0 trabalho de Mattoso (1985) examina as práticas violentas de trote aos ingressantes no ensino superior, no Brasil, ainda no século XIX. 
ção do Estado na condição de problema social. Por essas razões, busca-se considerar o diálogo e a interação que a própria produção de conhecimento realiza com os processos sociais que a circundam e as possibilidades de sua interferência no campo das orientações dos atores. ${ }^{5}$

\section{A constituição do tema da violência escolar no espaço públic o}

Conforme atestam alguns estudados realizados (Martins, 1996; Zaluar, 1999; Peralva, 1997a, 2000), o tema da violência, sobretudo aquela que ocorre nos grandes centros urbanos na sociedade brasileira, é parceiro do processo de democratização, à medida que, a partir do início dos anos 1980, essa questão eclode com força no debate público. Isso acontece, de um lado, porque demandas latentes adquiriram vi sibilidade nos espaços possibilitados pela distensão política, propiciando maior abertura para as questões que afetavam a qualidade de vidada po pu lação das periferias das gran descidades, onde a segurança constituía problema importante e até hoje não resolvido. De outro, tratava-se, naquele momento, de lu tar poruma maior democratização das instituições oficiais - sobretudo do aparelho de segurança - resisten tesaosno vosru mostri lha dospelo país. Mas é preciso reconhecer que a elevação da violência à condição de problema nacional no debate público decorre também de sua disseminação e diversificação no âmbito da sociedade civil. ${ }^{6}$

É no quadro deumaam plademan da desegurança por parte dos moradores das periferias doscen trosurbanosqueo fenômeno davio lên cia nos estabelecimentos escolares torna-se visível e passa a acompanhar a rotina do sistema de ensino público no Brasil, desde o início dos anos 1980. Nesse momento, a mídia, sobretudo a imprensa escrita e a televisão, age como espaço possível de ressonância de denúncias que afetavam a vida dos estabelecimentos escolares situados na periferia de cidades como São Paulo. Em geral, o tom predominante era 0 de expor as precárias condições dos prédios quanto aos equipamentos mínimos de proteção. Eram denunciadas, também, as constantes depredações dos edifícios e invasões, observadas nos períodos ociosos, em especial nos fins de semana.

A cidade de São Paulo constitui um bom exemplo da disseminação das demandas desegurança nos estabelecimentos situados em regiões periféricas. As reivindicações dirigidas aos primeiros governos eleitos pelo voto popular, no início dos anos 1980, reuniram professores, alunos e pais que buscavam melhores condições de funcionamento das unidades escolares. As respostas, em geral, resultavam em algumas medidas como: policiamento nas áreas externas, zeladorias, muros, iluminação nas áreas externas e pátios esco lares, gradesemjanelas, portõesal tos, etc.

Nesses primeiros anos da década de 1980 observa-se certo consenso em torno da idéia de que as unidades escolares precisavam ser protegidas, no seu cotidiano, de elementos estranhos, os moradores dos bairros periféricos, atribuindo a eles a condição de marginais ou delinqüentes. Tratava-se assim de uma concepção de violência expressa nas ações de depredação do patrimônio público, especialmente, e, em menor grau, no medo da invasão dos prédios por adolescentes ou jovens moradores, aparentemente sem vínculo com a unidade escolar.?

5. As orientações defendidas por Debarbieux e Montoya apoiam-se largamente nos estudos empreendidos por Chamboredon (1972) quando examina o tema da delinqüência juvenil, pois Débarbieux considera que esse autor "não constrói uma nova apresentação de uma delinquência pré-existente às pesquisas que a descobririam, como um atributo ou uma essência individual. Ele tenta a construção do objeto delinquência que é desconstrução/reconstrução da emergência social do fenômeno" (Debarbieux, 1998, p.94) (minha tradução).

6. Peralva, entre outros, observa que a violência a partir dos anos 1980, com exceção no meio rural, deixou de ser eminentemente política abrindo caminhos para a delinqüência, criminalidade e práticas de justiça extra-legal como os linchamentos e justiceiros (Peralva, 1997a, p. 217).

7. Eventualmente as práticas eram consideradas como formas de ressentimentos de ex-alunos, excluídos precocemente da escola. 
Naquele momento não estavam sendo questionadas as formas de sociabilidade entre alunos, mas eram criticadas as práticas internas aos estabelecimentos escolares produtoras da violência.

Marcada pela conjuntura, a discussão da violência da escola esteve indissociavelmente ligada à questão democrática. De certo modo tratava-se de buscar um modelo mais democrático de gestão dos estabelecimentos, incorporando alu nos, paise dema isusuá ri os na to ma da dedecisões. Buscava-se uma instituição mais aberta, menos autoritária em suas práticas e propiciado rademelho rescon di ções depermanên ciados alunos mais po bresno sistemaformal deen sino.

Desde os primeiros anos da década de 1980, o Poder Público tentou responder ao clima de insegurança com dois tipos de medidas: de um lado, aquelas relativas à segurança dos estabelecimentos, cada vez mais sob responsabilidade das agências policiais e, de outro, as iniciativas de cunho educativo, que tentavam alterar a cultura escolar vigente, tornando-a mais permeável às orientações e características dos seus usuários.

Durante a década de 1980 e início dos anos 1990 o tema da segurança passa a predominar no debate público. Os eixos fortes que articulavam a discussão da escola pública em torno deumadesejadaaberturademo cráticase arrefecem.

Nesse período, não obstante a adoção de medi daspon tu ais, o pro blemadavio lên cianasescolas persistiu, sob a forma de depredações contra os prédios, invasões e ameaças a alunos e professores. Mas o clima de insegurança agrava-secoma intensificação da ação do crime organizado e do tráfico em algumas cidades brasileiras. Aumentam a criminalidade e 0 sentimento de insegurança, sobretudo nos bairrosperiféricos, e, dessaforma, a vida escolar passa a sofrer de forma mais nítida os impactos dessa nova conjuntura. Essas questões tornaram-se mais visíveis em cidades como o Rio de J aneiro, mas estão presentes, também, em outros centros urbanos.
A imprensa e a mídia televisi vapassama dar uma cobertura esporádica ao fenômeno da violência, privilegiando os homicídios que ocorrem nas cercanias ou no interior dos prédios escolares, e os eventos que passam a ser notícia são aqueles que fogem das rotinas já noticiadas, como os incêndios de escolas provocados por ex-alunos. Observa-se, nos anos 1990, que a violência escolar passa a ser observada nas interações dos grupos de alunos, caracterizando um tipo de sociabilidade entre os pares ou de jovens com o mundo adulto, ampliando e tornando mais complexa a própria análise do fenômeno. As noticias e estudos realizados já dão conta da presença de ocorrências em várias regiões do país, alcançan do ci dadesdemédio porte, in clu in do capitais e outros centros.

A partir de meados da década de 1980 atin gin do osúl ti mosanos da déca da de 1990 , a violência nas escolas foi peremptoriamente considerada como questão de segurança, arrefecendo as propostas de teor educativo, com raras exceções por parte de governos locais (estaduais ou municipais) de cunho progressista.

A expansão de administrações municipais e estaduais de orientação de esquerda ou de centro-esquerda no país marca os últimos anos da década de 1990. Esse é um período marcado por um grande número de iniciativas públicas preocupadas em reduzir a violência nas escolas. Algu masocorrem em parceriacom organizações não governamentais - ONG's ou movimentos da sociedade civil. Trata-se, assim, de fenômeno bastante emergente, que merece, ainda, uma série de estudos capazes de avaliar seu impacto. ${ }^{8}$ Além de enfatizar as

8. Somente a partir de 1999 tornam-se visíveis algumas ações empreendidas pela Secretaria Nacional de Direitos Humanos do Ministério da J ustiça, que lança uma campanha de desarmamento para ser divulgada sobretudo na rede escolar e mídia e o Programa Paz nas Escolas caracterizado por uma série de iniciativas: capacitação de professores e policiais em direitos humanos, ética e cidadania e programas de formação voltados para a gestão de conflitos tendo, como público-alvo, jovens e corpo policial. 
propostas de cunho educativo, de certo modo retomando o quadro de debates em torno da idéia de maior democratização da cultura dos estabelecimentos escolares, as iniciativas mais recentes procuram desenvolver novas concepções em torno do tema da segurança, tradicionalmente distante do universo de preocupações dos segmentos progressistas, que centraram suas plataformas de ação em torno das políticas sociais.

\section{Os primeiros estudos na década de 1980}

Os primeiros passos mais sistemáticos para a compreensão do fenômeno decorrem de iniciativas disper sas do Po der Pú bli co em registrar as ocorrên ciasdevio lên cianas es co laspara esboçar um quadro mais realista de sua magnitude e extensão.

A precariedade das informações é significativa e decorre de uma série de fatores. 0 primeiro diz respeito à ausência de continuidade nas formas de registro e de monitoramento do fenômeno. Cada gestão encontra seus próprios procedimentos ou, muitas vezes, não empreende a tarefa do acompanhamento sistemático tendo em vista o grau encontrado de dificuldades. As unidades escolares resistem em cumprir determinações de registrar as ocorrências e as razõesdisso oscilam muito, depen den do do clima dominante na rede pública: houve épocas em que a notificação de episódios de violência evidenciaria as eventuais fragilidades do trabaIho pedagógico das escolas; em outras ocasiões, a notificação poderia redundar em ganhos adicionais aos estabelecimentos como maiores recursos materiais e humanos ou em algumas vantagens salariais a professores que trabalhassem em áreas de risco.

Os primeiros diagnósticos baseados em levantamentos parciais sempre apontaram as depredações, furtos e invasões em períodos ociosos como os grandes problemas dos anos 1980 em cidades como São Paulo, Salvador, entre outras (Sposito, 1994, 1999; Pinto, 1992, Sarmento, 1987). ${ }^{9}$

Sob o ponto de vista da produção acadêmica na pós-graduação em Educação, 0 tema da violência foi abordado em toda a década apenas por duas pesquisadoras. Uma delas, em suas pesquisas de mestrado e doutorado (Guimarães,1984, 1990), investigou escolas públicas da cidade de Campinas, localizada no interior do estado de São Pau 10. ${ }^{10}$ Os trabalhos utilizam-se de aproximações qualitativas, cujo eixo foi o estudo de unidadesescolares, acom panhan do suas ro tinaspor meio de observações e entrevistas com professores e alunos. Deslocando o foco do tema da segurança, as primeiras pesquisas acadêmicas privilegiam a violência que parte das práticas dos estabelecimentos escolares, consideradas autoritárias e, portanto, estimuladoras do clima de agressões, traduzido principalmente pelas depredações e também pelas invasões dos espaços escolares e brigas entre os grupos, nem sempre identificados como de alunos. ${ }^{11}$

A primeira pesquisa realizada por Guimarães (1984) oferece um quadro bastante sugestivo ao contrariar hipóteses dominantes no período que propunham ser a violência em meio escolar decorrência do controle e vi-

9. Os dados sempre oscilaram em torno de $40 \%$ em relação ao número de estabelecimentos que sofriam algum tipo de violência, sendo mais acentuadas as áreas urbanas e grandes cidades.

10. Embora todos os diagnósticos produzidos pelo Poder Público durante a década confirmassem a hipótese de uma maior intensidade da violência nas escolas situadas na região metropolitana de São Paulo, não é possível desconsiderar a presença desse fenômeno em cidades de porte médio como Campinas.

11. Moura (1988) também realiza estudo qualitativo de mesma orientação interpretativa. Nesse momento tanto a noção de violência simbólica, ancorada em Bourdieu (1975), como os estudos de Foucautl (1987) são utilizados como fonte interpretativa. 0 primeiro autor inspira a crítica dos aspectos pedagógicos, sendo a noção de violência simbólica utilizada de forma bastante ampla e às vezes imprecisa. Foucault inspira as análises que tratam tanto dos mecanismos disciplinares como dos micropoderes envolvidos na cultura escolar.

12. De um conjunto de 75 escolas públicas estaduais urbanas, a autora selecionou, por amostragem e sorteio aleatório, 15 unidades entrevistando 30 alunos de $1^{\underline{a}}$ a $8^{\text {a }}$ série. 
gilância exercido por pro fesso resedemaisprofissionais das unidades escolares. 0 trabalho de campo ${ }^{12}$ havia evidenciado que esse fenômeno estava presente tanto em escolas altamente rígidas sob 0 aspecto disciplinar quanto em escolas permissivas e desorganizadas. Em seu segundo estudo a autora verifica, já no final dos anos 1980 que a intensificação do policiamento resultava na diminuição dos índices de depredação escolar, sendo perceptível, ao mesmo tempo, o aumento das brigas físicas entre alunos. ${ }^{13}$

\section{A pesquisa nos anos 1990}

Os diagnósticos e algumas pesquisas de natureza descritiva sobre a violência escolar são produzidos ao longo da década de 1990 por al gumasorganizaçõesnão-governamentais e entidades de profissionais da educação (sindicatos docentes e associações de diretores de escolas), seguidos por al gunsestu dosem preendidos por organismos públicos.

Os levantamentos nacionais observados no final da década de 1990 apresentam uma peculiaridade. Não são estudos voltados de modo privilegiado para o exame das relações entre violência e escola. Os mais freqüentessão grandes surveys que se realizam com jovens moradores de capitais, onde suas relações com a violência são examinadas no interior de outras variáveis. Registra-se apenas um único estudo nacional realizado sobre condições de trabalho com professores da rede de ensino público, no qual o tema da violência e segurança nas escolas é abordado.

Partesignificativadediagnósticosquantitativos sobre juventude tem sido conduzida por organizações não-governamentais e por alguns institutos de pesquisa. Dentre esses destaca- sea Unesco, que empreende, em parceria com várias instituições, pesquisa nacional sobre jovens no Brasil, envolvendo as capitais. ${ }^{14}$ Tais pesquisas nascem particularmente a partir de 1997, o que configura claramente uma preocupação em decifrar certas condutas violentas de jovens, que atingem, tam bém, osseto resmédios. ${ }^{15}$ Embora poucas, al gu mas dasquestõessão di ri gi dasaos jovens e seus educadores sobre o tema da violência na escola.

A primeira pesquisa realizada pela UNESCO com jovens de Brasília apontava que esses segmentos estavam mais envolvidos do que as meninas em situações de agressões físicas, discussões e ameaças ou intimidações no in teri orda esco la. Desses trêsti posdeconduta, a mais freqüente incidia sobre as discussões (quase $55 \%$ do total de entrevistados se en vol via comessetipo de prática mu itasvezes ou às vezes, ocorrendo poucas diferenças entre homens e mulheres). As ameaças e intimidações envolviam $28 \%$ dos meninos muito freqüentemente ou mais raramente e apenas $10 \%$ das meninas. As agressões físicas ocorriam em menor número, pois há porcentagensbastan teeleva das dejo vensquenun ca se envolveram $(72 \%$ dos jovens e $93 \%$ das mulheres jovens) ((Waiselfisz, 1999, p.62).

0 levantamento realizado em 1997 (Abramovay e outros, 1999) envolvendo jovens das cidades da periferia de Brasília indicava que para $37,3 \%$ desses segmentos a escola não era local de violência; quase metade considerava a instituição como âmbito de média violência; e $16 \%$, de muita violência. Esses jovensclassificaram como muito violentos: a televisão, os bai les, festaseshows. Den tre todos os ambientes citados, apenas a família é indicada, por ampla maioria (75\%

13. Em seu estudo, Moura (1988) recorre a uma concepção ampla da violência, analisando os mecanismos de controle e punição e as formas cotidianas da linguagem que não respeitariam a experiência que 0 aluno traz de seu meio.

14. A Fundação Perseu Abramo também realizou pesquisa nacional com os segmentos jovens (Venturi e Abramo, 2000). As pesquisas conduzidas pela UNESCO ainda se encontram em andamento, mas os resultados de algumas cidades já estão publicados: Brasília, Rio de J aneiro, Curitiba e Florianópolis.

15. Em 1997, um índio pataxó é queimado e assassinado por cinco jovens de camadas médias da cidade de Brasília, ocasionando um grande debate público, em âmbito nacional. A partir dessa data 0 Ministério da J ustiça começa a voltar suas atenções de forma mais sistemática para o tema da violência entre os jovens. 
dosentrevistados), como lo cal denão-violência (Abramovay e outros, 1999, p.61).

A pesquisa na cidade do Rio de Janeiro revelou alguns resultados peculiares, fora do padrão do sen so co mum, poismedi an teestratificaçãoso cial do universo investigado em cinco grupos, foi possível verificar que os jovens dos estratos privilegiados ( $A$ e $B$ ) relataram maior número de ocorrências de ameaças $(19,2 \%$ estratos A e B; $18,6 \%, C, D$, e E) e de agressõesfísicas (28\% A e B; $23,3 \%, C, D$, e E) do que os de origem popular (Minayo, 1999).

0 único levantamento nacional que abordou o tema da violência escolar, publicado em 1998, traz um retrato bastante sugestivo,embora tenha sido decorrente de uma investigação realizada apenas com professores (Codo, 1999). ${ }^{16}$ Três tipos de situações foram identificadas como as mais freqüentes: as depredações, furtos ou roubos que atingem o patrimônio, as agressões físicas entre os alunos e as agressões de alunos contra os professores. Os índices dos estados quanto ao vandalismo, furtos e roubos, oscilam numa escala de $68 \%$ no Pará, na região Norte, a 33\% em Alagoas, na região Nordeste. Aparentemente, não há correlação entre nível de desenvolvimento socioeconômico de determinado estado e os índices de depredação, mas a pesquisa verificou que os estabelecimentos de maior tamanho (com mais de 2.200 alunos) são os mais suscetíveis a essas práticas, acentuando-se aqueles que são localizados nas capitais. Segundo os autores, a pesquisa

tambémevidenciou que não existe relação entre a maior extensão de recursos de segurança interna nas escolas públicas brasileiras e as ocorrências de roubo e/ou vandalismo nos estabelecimentos, ou melhor, a existência de maiores problemas de vandalismo coincide exatamente com a presença de segurança ostensiva (Codo, 1999, p. 155). ${ }^{17}$

As agressões a alunos dentro da escola são registradaspelosprofesso resen trevistados, variando a intensidade por estado da federação. Os índices mais altos incidiram sobre 0 Distrito Federal $(58,6 \%)$ e os menores sobre 0 esta do de Go iás (8,5\%). Asagres sões a pro fessores no interior do estabelecimento são também registradas pelos sujeitos investigados, mas em menor nú mero: Mato Grosso éo estado em que os professores relataram o maior número de agressões (33\% dos entrevistados) e o Rio de J aneiro (1,2\%) apresenta os menores índices. Do mesmo modo, as práticas de agressões, tanto entre os alunos como contra ospro fesso res, são maisco munsnosestabelecimentos de grande porte e nas capitais (Batista e El-Moor, 1999, p. 151-153).

Embora os resultados sejam bastante fragmentários, é possível considerar que os anos 1990 apontam mudanças no padrão da violência observada nas escolas públicas, atingindo não só os atos de vandalismo, que continuam a ocorrer, mas as práticas de agressões interpessoais, sobretudo entre 0 público estudantil. Dentre estas últimas, as agressões verbais e ameaças são as mais freqüentes. 0 fenômeno alcança as cidades médias e regiões menos industrializadas e não é evitado a partir de medidas de segurança interna aos estabelecimentos.

Como as práticas mais violentas entre os alunos passam a se disseminar, no final da década observa-se um interesse, ainda que bastante incipiente, para a realização de pesquisas sobre vitimização no ambiente escolar. A investigação desenvolvida pelo ILANUD Instituto Latino Americano das Nações UnidasparaPreven ção do Deli to eTrata men to do Delinqüente - em escolas públicas na cidade de São Paulo consti tui uma daspou casini cia-

16. 0 universo da pesquisa foi constituído por 52.000 profissionais dos sistemas públicos de ensino, distribuídos em todo o país. 0 trabalho de campo teve início em 1997 e foi produto do apoio da CNTE Confederação Nacional dos Trabalhadores em Educação, UNICEF e CNPq.

17. A segurança externa, por sua vez, apresenta uma correlação importante com a diminuição dos índices de depredação e de vandalismo. 
tivas voltadas para essa questão (ILANUD, 2000). ${ }^{18}$ De modo geral, observa-se que, do total de alunos, as modalidades mais freqüentes de vitimização foram o furto de objetos de pequeno valor dentro da escola $(48,1 \%$ dos alunos), ameaça de agressão (36,5\%), pertences danificados $(33,1 \%)$ e agressão física por colega $(4,6 \%)$. As violações auto-assumidas (self reported ofenses) incidiriam sobre $25,4 \%$ dos alunos, que afirmaram de alguma forma ter depredado a escola; $1,9 \%$, que declararam ter levado armas de fogo; e 8,9\%, armas brancas. ${ }^{19} \mathrm{~A}$ pesquisa concluía que os poucos diagnósticos realizados revelam que as unidades de ensino não vivem "um quadro de violência generalizada. Comportamentos como ir a escola portando arma de fogo são bastante raros entre os estudantes paulistas" (IIlanud, 2000).

A década de 1990 foi também mais promissora sob o ponto de vista da produção do conhecimento, no interior da universidade, sobre o tema da violênciaescolar. Aparecem, nesse período, um conjunto de estudos expressos pelastesese disser tações naárea da Edu ca ção ${ }^{20}$ e algumas investigações realizadas por equipes universitárias (Candau, 1999). Algumas delas a partir de demandas do Poder Público (Fukui, 1991; Tavares dos Santos, 2000). ${ }^{21}$

Nesse momento, parte importante da pesquisa acadêmica procura examinar as relações entre a violência que ocorre nos bairros periféricos e favelas de alguns cen trosurbanos, sobretudo em regiões de domínio do crime organizado ou do narcotráfico, e a vida escolar. Destacam- se, nesse quadro, os estudos realizados na cidade do Rio de J aneiro (Costa, 1993; Rodrigues;1994, Guimarães 1995; Paim, 1997, Cardia, 1997). ${ }^{22}$

Esses trabalhos trazem questões importantes para a compreensão das relações entre a violência e escola, apontando, principalmente, a influência do aumento da criminalidade e da insegurança sobre os alunos e a deterioração do clima escolar. Guimarães (1995) investiga a ação das galeras funk e do narcotráfico nas escolas públicas da cidade do Rio de J aneiro. A autora apresenta relato, de cunho etnográfico, que descreve a instituição escolar como refém do crime organizado, mas, ao mesmo tempo, como espaço de disputa entre grupos de jovens pertencentes a galeras rivais. ${ }^{23} \mathrm{~A}$ lógica do tráfico, que busca a ampliação do seu domínio territorial, e a lógica das galeras, que bus cam ex pan dir o raio de suas ações a fim de secon so lidaren quan to gru po, in va dema unidade esco lar, im pedin do a sua ação edu cativa. Esse processo resulta em ampla frustração de expectativas das classes populares que ainda acreditam na educação escolar como instrumento de democratização social.

0 tráfico de drogas e a disputa pelos territórios nos morros são considerados as gran descau sas da onda de vi o lên cia nas escolas públicas do Rio de J aneiro pelas pesquisas de Costa (1993), Rodrigues (1994), Paim (1997) e Guimarães (1995). ${ }^{24}$ No entanto, os

18. A pesquisa foi realizada em quatro escolas públicas e três particulares, envolvendo 1.026 alunos da cidade de São Paulo.

19. Maior parcela afirmou ter visto alguma vez colegas portando armas de fogo $(14,6 \%)$ e armas brancas $(36,1 \%)$.

20. O levantamento da produção discente até 1998 foi realizado em caráter exaustivo, em âmbito nacional. A partir dessa data há um conjunto novo de trabalhos aqui incorporados, sem a pretensão de abranger todo 0 universo possível.

21. Aparecem também nesse período artigos e livros dedicados ao tema da violência escolar que, embora não retratem diretamente resultados de pesquisa, examinam reflexivamente a questão, sob aportes teóricos diversos (Ver Cadernos Cedes 47, Morais, 1995). Os estudos desenvolvidos por Alba Zaluar em torno da criminalidade, tráfico e juventude no Rio de J aneiro, são marcos significativos para a compreensão da violência no Brasil. Algumas de suas pesquisas examinaram as relações dos jovens com a escola, tendo sido tratada, também, a questão da violência (Zaluar, 1985, 1994; Zaluar e Leal, 1997).

22. A respeito do crime e a organização do tráfico consultar Zaluar (1985 e 1994), Peralva (2000), Velho e Alvito (1996).

23. Guimarães também distingue o fenômeno do narcotráfico do fenômeno das galeras, uma vez que, apesar de algumas conexões, estas não podem ser consideradas como desdobramentos juvenis da ação criminosa, sendo, principalmente, uma forma de prática coletiva marcada pela sociabilidade de moradores jovens de favelas no Rio de J aneiro.

24 . No entanto, essa situação provoca muitas vezes, por parte das unidades escolares, certa recusa de aceitação do fenômeno (Costa,1993; Rodrigues,1994), marcada pelo medo de falar sobre uma realidade diretamente relacionada à violência: a guerra do tráfico, incrustada nas comunidades em que os estabelecimentos se localizam. 
estudos também reconhecem os ef eitos da banalização da violênciaso breasociabilidadedos alunos e a existência de um clima tenso entre adultos e adolescentes ou dos alunos entre si que afeta o conjunto da atividade escolar (Rodrigues, 1994; Costa, 1993; Cardia, 1997). ${ }^{25}$

Partindo da investigação das percepções da violência no bairro, Cardia (1997) examina seus possíveis efeitos sobre a vida escolar. Em áreasmarca dasporocor rên cias deho mi cídi oso clima de medo invade as rotinas escolares. Em locais onde há menor intensidade, mas outras práticas violentas, sobretudo aquelasqueocorrem no interior da família, verifica-se o fenômeno da normalização da violência, ou seja, sua banalização. Esse clima observado nos bairros atinge as escolas investigadas, onde são comuns as práticas de incivilidade, tais como brigas, agressões físicas e verbais. Mais da metade dos alunos julgava que a violência vinha crescendo, muitos deles sendo testemunhas de delitosobservadosnosbairros. Muitosconsideravam que as unidades escolares, no seu conjunto, apresentavam menor grau de violência do que o bairro.

Can dau (1999) in vestigou, tam bém nacidade de Rio de J aneiro, o tema da violência escolar no universo dos professores da rede pública. ${ }^{26}$ Reconhecendo o aumento da violência escolar como mais uma das expressões do aumento da violência social, a maioria dos entrevistados apontou a prática de agressões físicas e verbais entre os alunos como uma das modalidades mais freqüentes encontradas na sua experiência de trabalho. No entanto, alguns também relataram a presença desse tipo de conduta partindo do mundo adulto (funcionários e professores). ${ }^{27}$ As depredações e agressões ao patrimônio, como é o caso das pi cha ções, tam bém fo ram apon ta daspelosprofessores, sendo menor a freqüência de situações de roubo e de intimidação de agentes externos à escola (chefes locais do crime).

Esse conjunto de trabalhos sobre a experiência da violência e a relação com o universo escolar na cidade do Rio de J aneiro, ${ }^{28}$ realizados por pesquisadores isolados, apresentam um quadro importante para a caracterização do fenômeno no universo social e o ambiente escolar estudados, particularmente para as uni da des deen si no si tu a dasem regiõesdo minadas pelo crime organizado. Nesse caso, a violência observada na escola retraduz parte do ambiente externo em que as unidades escolares operam, particularmente em localidades dominadas pelo crime organizado. No entanto, dada a inexistência de um programa conjunto de pesquisas, torna-se difícil estabelecer comparações entre realidades sociais, culturais e urbanas, compreendendo outras regiões e cidades brasileiras. ${ }^{29}$

Outro centro urbano que foi foco de interesseda pro du ção discen tena pós- gradua-

25. Maria Regina Castro (1998) discute em seu mestrado as representações de crianças e adolescentes a respeito da violência. 0 grupo de sujeitos investigado foi composto por quatorze alunos de uma escola pública e dez de uma escola particular do município do Rio de J aneiro, com idades entre 10 e 19 anos. Observou que, na escola particular freqüentada pelas classes médias, 0 eixo articulador das representações é o crime e os alunos se percebem como vítimas da violência; como estão mais distantes dessas práticas em seu cotidiano, são capazes de fazer projetos de futuro e mantêm uma auto-estima positiva. Na escola pública, o eixo é a morte e os alunos não se percebem nem como vítimas nem como agressores; seu cotidiano é marcado pela violência e pela proximidade da morte, 0 que dificulta a elaboração de projetos de futuro.

26. O estudo, de natureza qualitativa, caracterizou-se pela realização de 31 entrevistas com professores de escolas públicas que atuavam em regiões violentas, sendo quatro deles com aulas também na rede particular de ensino. Três, dentre as cinco unidades investigadas, estavam localizadas em regiões dominadas pelo narcotráfico.

27. Reiterando as percepções registradas por Cardia (1997), professores também consideram que a presença da violência familiar acaba por afetar o clima da escola, sobretudo o trabalho em sala de aula, prejudicando o rendimento escolar.

28. Essas pesquisas recorrem a procedimentos de natureza qualitativa tendo a unidade escolar como eixo fundamental do trabalho de campo.

29. Fukui (1991), a pedido da SEE/SP realizou estudo de caso em três estabelecimentos escolares da região metropolitana de São Paulo, identificando a partir do corpo profissional e dos alunos os vários sentidos da expressão segurança na escola e as sugestões para a superação do quadro insegurança. Medidas de ordem material relativas aos prédios, número de alunos por classe e por escola e alteração de algumas práticas pedagógicas foram as demandas mais freqüentes observadas pelo estudo. 
ção é Porto Alegre, cidade de médio porte (em torno de 1,2 milhões de habitantes), localizada no sul do país. Sobre ela, três dissertações de mestrados foram realizadas, sendo a primeira delas (Oliveira, 1995) de natureza comparativa, na qual fo ram in vesti gadasas diferen tespercepções que alunos de escolas públicas e particulares têm sobre a violência no interior das práticas escolares. $^{30}$

Há dois estudos sobre escolas mantidas pela prefeitura da cidade de Porto Alegre, que revelam peculiaridades importantes no exame da questão das relações entre violência e escola no Brasil (Costa, 2000; ${ }^{31}$ Paim Costa, 2000). Ambos realizaram trabalho de campo em unidades escolares localizadas em bairros marcados por alto grau de violência social, situados na periferia da cidade. As investigações de natureza qualitativa evidenciam a existência de estabelecimentos escolares atuantes, cujas equipes profissionais formulavam projeto pedagógico apoiado nas orientações da administração municipal. ${ }^{32}$

Nessas pesquisas é reconhecida a presença cotidiana de atos marcados também pelas agressões verbais, embora para grande parte dos atores envolvidos, inclusive pais, o sentido da violência esteja eminentemente ligado à coação física. Cercadasporumambien tehostil, as unidades mantêm relações com os pais que tendem a se aproximar da escola e que buscam um lu gar segu ro para a edu ca ção deseusfi lhos. As rivalidades entre grupos juvenis que expressam a segmentação da região em unidades territoriais bastante conflituosas e as brigas entre os alunos afetam a execução do projeto educativo da escola, revelando certa perplexidade do grupo de professores, que apresenta dificuldades em superar a questão. ${ }^{33}$

Investigação conduzida pelo Instituto de Filosofia e Ciências Humanas/UFRGS, em parceriacom a prefeitu ra dePorto Alegre(Tavares, 1999), procurou sistematizar os episódios de violência observados na rede de escolas municipais a partir de $1990 .{ }^{34}$ Do total de registros
(204), o maiorín dice recaiu so breasagressões contra a pessoa (60\% das ocorrências), compreendendo as lesões corporais, roubo (carros, dinheiro) e brigas e invasões no espaço escolar.

Ampliando o universo geográfico de in vestigação, estudos recentes desenvolvidos em outras cidades brasileiras trazem elementos novos para a constituição do tema enquanto objeto de investigação.

A dissertação de mestrado desenvolvida em escola pública de Belo Horizonte (Araújo, 2000 ) privilegia os episódios de violência observados na unidade escolar, que traduzem a experiência de afrontamento de moradores de bairros geograficamente próximos, mas distantes simbolicamente em razão da rivalidade e de formas de conflitos cotidianos. Sendo freqüentada por jovens de bairros diferentes, um deles estigmatizado pelos índices de violência e criminalidade, a escola enfrentava problemas internos graves que dificultavam a condução da atividade pedagógica. 0 estudo inova porque investiga as formas de constituição da identidade desses adolescentes que experimentam não só a violência no seu cotidiano, mas o estigma no interior da escola em decorrência do seu lugar de moradia. MerguIhados em ambientes de extrema insegurança e medo, os jovens desenvolvem algumas

30. Foram aplicados questionários em 148 alunos de $7 \underline{a}$ e $8^{\underline{a}}$ séries da escola particular e em 88 alunos das mesmas séries da escola pública.

31. 0 trabalho de Costa elegeu como sujeitos da investigação crianças entre 8 e 13 anos, integrantes de turmas que apresentavam sérios problemas de aprendizagem, que se pronunciaram quanto à sua experiência de violência na família, no bairro, na escola. Eram reconhecidos na escola como grupo de alunos com sérios problemas de agressividade.

32. Trata-se do projeto Escola Cidadã, que busca alterar práticas e orientações das escolas municipais a partir de novas propostas pedagógicas em torno de um ideal cidadania voltada para os segmentos populares que situa a escola como direito.

33. 0 estudo de Paim Costa apresenta também um quadro de vitimização forte por parte de vários alunos, não só no ambiente escolar como na família.

34. A coleta sistemática dos registros ocorreu a partir de 1995 (Santos, 1999). 
estratégias na busca de segurança e formação da identidade pessoal que recusam, algumas vezes, formas grupais de sociabilidade, comuns nessa faixa etária. Ao perceber apoio apenas no grupo familiar e em poucos amigos, os jovens tentam lidar com a própria ambigüidade dessa situação. Ao serem estigmatizados pela origem de sua moradia, procuram retirar alguma vanta gem dessasi tu ação dispon do- seao en fren tamento com os outros alunos, de modo a se impor pelo medo ou pela força. Assim, a violência observada na escola não é exclusivamente escolar, poisex primemenosuma rea ção à instituição do que a demarcação de espaços de poder, uma espécie de afirmação, pela violência, do direito de ser reconhecido, em situações de extremadesvantagem, decorrente do estigma. ${ }^{35}$

Laterman (2000) investigou duas escolas em Florianópolis, no sul do país, marcadas pela sensação de caos e deterio ração do clima diário das interações. Inspirada nos estudos franceses que recorreram à noção de incivilidade, a pesquisadora recompõe o quadro tenso das relações diárias e o mal-estar que atinge tanto alunos como professores. Em suas conclusões verifica que "não é possível afirmar que as incivilidades se somam ou se transformam, ao longo do tempo, em crimes, como se fossem uma gênese daqueles acontecimentos mais graves" (2000, p. 151). No entanto, ressalta 0 fato de que os limites anti-sociais das condutas, sendo ultrapassados, facilitam este indesejável avanço ao lado da afirmação da "ausência de poder (seja da sociedade em geral, dos educadores, dos pais, dos valores) que a isso se oponha" (p.152).

Camacho (2000), em seu doutorado, examina o tema da violência escolar na cidade de Vitória, capital do estado do Espírito Santo. Apesar de não ser uma grande cidade, ${ }^{36}$ Vitória apresenta altos índices de mortes violentas de jovens na faixa etária de 15 a 24 anos, ocupando, de acordo com a UNESCO, o primeiro lugar no ranking das capitais (Camacho, 2000). ${ }^{37} 0$ caráter inovador do estudo decorre do próprio universo de investigação, pois foram selecionadas duas escolas: uma particular confessional, destinada aos filhos das elites locais; e uma pública, freqüentada sobretudo por alunos oriundos de camadas médias. Mediante observações prolongadas e entrevistas com gru posdealu nos, a pes qui sa evi den cia mo dalidades diversas de relação entre os pares e destes com os adultos nas duas escolas investigadas. Descontentes com a interação mantida com os professores, os alunos da escola de elite optam por práticas de agressão, sobretudo verbais, na sala de aula, de maneira dissimulada aos olhos dos professores que, de modo geral, conduzem a aula sem grandes problemas com a disciplina. Os adolescentes da escola pública, que vivem um clima de indisciplina na sala de aula, encontram no recreio enas dema isho rasocio sasosmo men tos de expressão das práticas de agressões não só verbais como físicas. Se na escola particular o foco das práticas de violência incidem sobre aqueles que são portadores de diferençassensíveis diante dos grupamentos espontâneos formados (os negros, os suspeitos de homossexualidade, os mais gordos e feios), na escola pública os diferentes (reconhecidos a partir dos diferentes estilos de seus grupos e condutas que os definem como membros de gangues) agrupam-se e se firmam nessa situação ao praticarem agressões verbais e físicas contra seus pares.

0 conjunto, ainda que pequeno de trabalhos concluídos na década de 1990, sobretudo nos últimos anos, é revelador de uma quadro complexo regido pelas formas de vio-

35. Embora não trate do tema violência e escola, Monteiro (1998) em seu estudo de escolas públicas mostra a dificuldade dos professores e diretores em lidar com os alunos que explicitamente fazem parte de grupos juvenis, no caso estudado, de gangues.

36. Em 1996 Vitória possuía cerca de 265 mil habitantes; em 2000, cerca de 291 mil.

3 7. 0 estudo desenvolvido por Codo (1998) mostra que o estado do Espírito Santo ocupa o quinto lugar nas ocorrências de roubo e vandalismo escolar e $021^{\circ}$ no que se refere às agressões interpessoais. 
lência social que permeiam a vida urbana em bairros periféricos ou favelas ${ }^{38}$ das cidades brasileiras.

A instituição escolar tem sido permeável a esse quadro, sobretudo em regiões marcadas pela presença do crime organizado e do narcotráfico. Os estudos de Zaluar $(1985,1994)$ e Peralva (2000) têm evidenciado não só o poder que lideranças criminosas exercem sobre o cotidiano dos moradores como as múltiplas relações que decorrem de uma formain dividualista da sociabilidade voltada para o consumo, que afeta, em particular, os segmentos juvenis.

No entanto, o quadro da ausência de segurança e o incremento da criminalidade urbana por si só não traduzem a complexidade do fenômeno da violência em meio escolar. A ausência de um dispositivo institucional democrático no interior de algumas instituições públicas - como é o caso dos aparelhos da segurança, em particular, a polícia, articulada à fraca presença estatal na oferta de serviços pú blicos de natureza social destinado aos setores pobres - é um fator a ser considerado na intensificação das práticas violentas nos bairros e escolas.

Essas características que acompanharam o processo de transição democrática são aliadas, também, do processo de abertura das oportunidades escolares que absorveu amplo contingente de estudantes oriundos dos segmentos empobrecidos da sociedade, sobretudo no ensino fundamental e, mais recentemente, se refletindo sobre o crescimento das matrículas do en si no médio. Expan são do en si no pú blico sob condições precárias, expressas na ausência de investimentos maciços na rede de escolas e na formação dos docentes, soma-se à ausência de projetos educativos capazes de ab sorver essa nova realidade escolar. A crise econômica e as alterações no mundo do trabalho incidem diretamente sobre as atribuições que articulavam os projetos populares de acesso ao sistema escolar. A escola, sobretudo para a geração atual, desejosa de ter acesso aos padrões de consumo de massas, não aparece como canal seguro de mobilidade social ascendente para os mais pobres. Assim, uma profunda crise da eficácia socializadorada educação escolar ocorre nesse processo de mutação da sociedade brasileira, que oferece caminhos desiguais para a conquista de direitosno in terior da experiência democrática.

Mas os estudos reiteram a presença de formas violência voltadas contra a escola, so bretudo aquelas que dizem respeito às agressões ao patrimônio, durante os últimos vinte anos. Apontam, também, para um padrão de sociabilidade entre os alunos marcado por práticas violentas - físicas e não físicas - ou incivilidades que se espraiam para além das regiões e estabelecimentos situados em áreas difíceis ou precárias, atingindo, também, escolasparticulares destinadasa eli tes. Chama a atenção 0 fato de que mesmo estando disseminadas entre o conjunto dos alunos, 0 discurso acadêmico tende a agregar esses comportamentos em torno da conduta dos gruposju venis, sen do estesúl ti mosfortemente responsabilizados pela disseminação da violência no interior da escola. Episódios relatados por professores e às vezesregistradosde forma secundária nos estudos empíricos in dicam a presença de situações de extrema violência conduzida pelo conjunto do corpo

38. São ainda necessárias investigações que recortem, no interior das relações entre violência e escola, a temática do gênero e das etnias, aliadas ao universo da crescente presença, ainda pouco estudada no Brasil, dos grupos juvenis. 0 fenômeno das turmas masculinas é antigo e faz parte da cultura de rua, mas, nos últimos anos, novas formas vêm surgindo marcadas por práticas de violência que merecem ser estudadas, pois a priori sofreram a designação de "gangues" por parte da mídia e da opinião pública sem que estudos sistemáticos tenham sido realizados. Há, no entanto, algumas investigações importantes conduzidas no Rio de J aneiro por Vianna (1988), Guimarães (1995), Souto (1997), Cecchetto (1997, 1999) sobre as galeras funk; e por Diógenes, (1998) em Fortaleza. A pesquisa debruçou-se com maior ênfase sobre os grupos de estilo como rappers, punks, darks e gangues (Abramo, 1994; Sposito 1994a; Guerreiro, 1994; Kemp, 1993; Cecchetto, 1997, 1999; Costa, 1993; Souto, 1997; entre outros), restando ainda esse novo campo de estudos dos comportamentos coletivos juvenis. 
discente, configurando quase que um padrão de rebelião coletiva, ainda não estudado. Essas ocorrênciaspodem ser observadas em situações de ociosidade na escola, em decorrência das faltas dos professores ou quando há interrupção repentina do fornecimento de energia elétrica no período noturno. Em alguns minutos carteiras e todo o mobiliário escolar são destruídos por grande parte dos alunos presentes nos estabelecimentos. $^{39}$ Essas questões reiteram também a crítica que os estudos têm estabelecido em torno deafirmaçõesbastan tecorrentes que relacionam violência e pobreza como unidade indissolúvel.

Assim, para além do reconhecimento dos fenômenos da violência cotidiana sofrida pelos moradores da periferia absorvidos em graus diferençados pela escola, os estudos tendem a apontar uma forma de sociabilidade entre os pares, ou entre o mundo adulto e juvenil, marcada pelas agressões, tendendo a se aproximar da noção de incivilidade trabalhada por vários autores que examinaram a violência escolar na França(Débarbi eux1996; Charlot, 1997; Peralva, 1997). ${ }^{40}$

A percepção das tensões existentes entre alunos ou entre estes e o mundo adulto tem af etado o clima dos estabelecimentos escolares, especialmente a ação dos professores, que passam a sentir-se sob ameaça permanente, quer real ou imaginária. 0 medo do aluno leva o docente a uma freqüente demanda de segurança, particularmente policial, nas unidades escolares,comprometendo a qualidade da interação educativa. Por outro lado, as práticas de agressão muitas vezes situam-se no limiar dos delitos criminosos, uma vez que no Brasil o acesso às armas de fogo é disseminado e, por essa razões, brigas juvenis podem facilmente resultar em homicídios.

Mas os estudos, ao indicarem a presença de práticas de incivilidade (recobrindo a violência física ou não física) em ou trosgrupossociais, mostram, também, que a crise da eficácia socializadora da escola recobre, de formas variadas, a experiência juvenil de diversas classes sociais na sua relação com o mundo adulto representado pela instituição escolar. Ou seja, as incivilidades sinalizariam, também, um conjunto de insatisfações manif estadas pelos alunos diante de sua experiência escolar e, ao mesmo tempo, as dificuldades da unidade escolar em criar possibilidades para que tais condutas assumam a forma de um conflito capaz de ser gerido no âmbito da convivência democrática.

A complexidade da pesquisa sobre violência em meio escolar no Brasil decorre, assim, da interseção com o tema da violência social, sobretudo nas cidades e na interação que o mundo do tráfico estabelece com os segmentos juvenis, alunos ou ex-alunos da escola pública. Mesmo estando articulados, um fenômeno não se dissolve no outro, exigindo instrumentos teóricos e recursos metodológicos de investigação capazes de facilitar a compreensão dessas conexões.

Por outro lado, os denominados conflitos entre grupos ou pares de jovens muitas vezes vêm propondo novos temas para a investigação, pois eles, em certa medida, estão dissociados dos fenômenos da delinqüência e da criminalidade. De modo gradual, a noção de incivilidade tende a ser incorporada pelo seu fecundo uso em outras situações e pát ses, ${ }^{41}$ indicando a ocorrência de pequenos delitos e transgressões que não se caracterizariam como atos de criminalidade ou delinqüência. Tal noção indicaria a crise de um padrão civilizatório ocidental, caracterizado pela contenção da agressividade e dos impulsos e pelo crescente papel do Estado

39. 0 fenômeno dos "apagões" tem sido observado nos centros urbanos a partir de 1997, sobretudo na região Sudeste. 0 episódio de destruição das carteiras durante a falta de energia elétrica foi relatado à autora em 1997 por professora de história do período noturno de escola pública da cidade de São Paulo.

40. Para Debarbieux a noção de incivilidade recobre uma série de práticas cotidianas expressas nos pequenos delitos, nas agressões verbais, na falta de polidez, nas ameaças e nas freqüentes irrupções de desordem nos estabelecimentos escolares (1996).

41.0 estudo de Laterman (2000) constitui um bom exemplo. 
como instância que reúne o monopólio da força e da coerção (Elias, 1989). No exame da situação brasileira, alguns cuidados merecem ser considerados, pois o seu uso indiscriminado pode acentuar apenas um dos pólos da questão - os alunos - e descaracterizar uma série de problemas contidos na relação entre o mundo adulto e 0 juvenil, sendo o primeiro muitas vezes incapaz de estabelecer práticas capazes de gerir 0 inevitável conflito entre os grupos etários, sobretudo nos mo men tosdecrisedeefi cá- cia das instituições socializadoras. Por essas razões, a pesquisa não está isenta da necessidade de investigar os processos amplos que configuram a expansão da escolaridade nos últimos anos, aliada à corrosão das possibilidades mais efetivas de mobilidade social e à crise da sociedade assalariada. Assim, a própria escola, enquanto campo de conflitividade que configura a interação entre jovens e instituições do mundo adulto, deve ser investigada e submetida à crítica.

\section{Referências bibliográficas}

ABRAM0, Helena. Cenas J uvenis: punks e darks no espetáculo urbano. São Paulo: Scritta, 1994.

ABRAM OVAY, Miriam e outros. Gangues, galeras, chegados e rappers. Rio de J aneiro: Garamond, 1999.

ARAÚj 0, Ma ria Car la de Ávi la. Vivências escolares de jo vens de um ba ir ro da pe ri fe ria de Belo Ho rizon te. Belo Ho rizonte; 2000. Dissertação (Mestrado) - Faculdade de Educação da UFMG.

BATISTA, Analia e EL-MOOR, Patricia. Violência e agres são. In: CODO, Wan der ley (co ord.). Educa ção: carinhoetra ba Iho. Rio de J aneiro: Vozes, 1999.

BOURDIEU, Pierre, PASSERON, J ean-Claude. A reprodução; elementos para uma teoria do sistema de ensino. Rio de J aneiro: Francisco Alves, 1975.

CADERNOS CEDES. Na mira da violência: a escola e seus agentes. CEDES, Campinas, n. 47, s.d.

CAMACHO, Luiza Ishiguro. Violência e indisciplina nas práticas escolares de adolescentes. São Paulo; 2000. Tese (Doutorado) Faculdade de Educação da USP.

CANDAU, Vera. Escola e violência. Rio de J aneiro: DP\&A Editora, 1999.

CARDIA, Nanci. A vi olênciaurba naea es cola. ContemporaneidadeeEducação. Rio deJ a ne iro: IEC, ano ll, n. 2, 1997.

CAIAFA, J anice. Movimento punk na cidade. A invasão dos bandos sub. Rio de J aneiro: Zahar, 1985.

CASTRO, Ma ria Regina Bor to lini de. A vida e a mor tenas represen ta ções de vio lên cia de crianças eado les cen tes. Rio de J aneiro; 1998. 100p. Dissertação (Mestrado em Educação) - Faculdade de Educação da UFRJ .

CECCHETTO, Fátima. As galeras funk cariocas: entre o lúdico e o violento. In: VIANNA, H (org). Galeras cariocas. Rio de J aneiro: Editora da UFRJ , 1997.

Ga le ras funk ca rio cas: os ba iles e a cons ti tu ição do ethos guer re iro. In: ZALUAR, Alba e ALVITO, Marcos. Um século de favela. 2a. edição. Rio de J aneiro: Fundação Getúlio Vargas, Editora, 1999.

CHAMBOREDON, J.C. La délinquance juvénile, essai de construction d'objet. Revue Française de Sociologie, XII, 1972.

CHARLOT, Bernard. Violences à l'école: état des savoirs. Paris: Armand Collin, 1997.

CODO. Wanderley (coord.). Educação: carinho e trabalho. Rio de J aneiro: Vozes, 1999.

COSTA, Eloísa Helena de Cam pos. A tra ma da vi olên cia na es co la. Rio deJ a nei ro; 1993.253p. Dis ser ta ção (Mes tra doem Educação) - Instituto de Estudos Avançados em Educação da Fundação Getúlio Vargas.

COSTA, Márcia Regina. Os Carecas do subúrbio: caminhos de um nomadismo moderno. Rio de J aneiro: Vozes,1993. 
COSTA, Marcia Rosa. Eu também quero falar. Um estudo sobre infância, violência e educação. Porto Alegre; 2000. Dissertação (Mestrado) na UFRGS.

DEBARBIEUX, E. La violence em milieu scolaire 1 - État des lieux. Paris: PUF, 1996.

DÉBARBIEUX, E e MONTOYA, Y. La violence à l'éco le en France: 30 ans de cons truc tion so cia loe de l'ob jet(1976-1997). Revue Française de Pedagogie. La violence à l'école: approches européennes. Paris: INRP, 123, 1998.

DIÓGENES, Glória. Cartogra fias da culturae davio lência. Gan gues, ga le ras e o mo vimen to hiphop. São Pau lo: Anna blu me, 1998.

ELIAS, Norbert. El proceso de la civilizacion. México: Fundo de Cultura Económica, 1993 (2 volumes).

FOUCAULT, Michel. Vigiar e punir. História da violência nas prisões. 11ạ edição. Petrópolis: Vozes, 1987.

FUKUI, Lia. Estudo de segurança nas escolas públicas estaduais de São Paulo. Cadernos de Pesquisa. Fundação Carlos Chagas, São Paulo, n. 79, novembro, 1991.

GUERREIRO, Goli. Retratos de uma tribo urbana: o rock brasileiro. Salvador: Centro Editorial e Didático da UFBA, 1994.

GUIM ARÃES, Áu rea Ma ria. Escola evio olên cia: Rela ções entrevigilân cia, pu nição ede predaçãoes colar. Campinas; 1984. 183p. Dissertação (Mestrado) - Faculdade de Educação da PUC de Campinas.

GUIMARÃES, Áurea Maria. A de pre da çãoes colar ea dinâmica daviolência. Cam pinas; 1990. 471 p. Tese (Dou to ra do) Faculdade de Educação da UNCAMP.

GUIMARÃES, Ma ria Eloísa. Escola, ga lerasenarcotráfico. Rio de J a ne i ro; 1995. 205 p. Tese (Dou to ra do) - PUC do Rio de J aneiro.

ILANUD - Insti tu to La ti no ame ri ca no das Na ções Uni das para a pre ven ção do de li to e tratamen to dodelin qüen te. Violên cia nas escolas. Revista do ILANUD, n. 16, 2000.

KEMP, Kênia. Gru pos dees ti lo jo vens: o rockun der ground eas práticas (con tra)cul tu ra is dos gru pos "punk" e "thrash" em São Paulo. Campinas; 1993. Dissertação (Mestrado) - IFCH da UNICAMP.

LATERMAN, Ilana. Violência e incivilidade na escola. Florianópolis: Letras contemporâneas, 2000.

MARTINS, J osé de Souza.Linchamento, o lado sombrio da mente conservadora. Tempo Social . Revis ta de So ciologiada USP, São Paulo, v. 8, n. 2, outubro de 1996.

MATTOSO, Glauco. Calvário dos carecas. História do trote estudantil. São Paulo: EMW Ediotres, 1985.

MINAYO, Maria Cecilia e outros. Fala Galera. Rio de J aneiro: Garamond, 1999.

MONTEIRO, Sueli Aparecida. Tentandocompreender Pro me teu e Di o ní sio na mira da violência. CEDES, Campinas n. 47, s.d..

MORAIS, Regis. Violência e educação. Campinas: Papirus Editora, 1995.

MOURA, Eliana Ribeiro de. Violência da escola. Piracicaba; 1988. Dissertação (Mestrado) - Faculdade de Educação da UNIMEP.

OLIVEIRA, Clau dia Reginade. Ofenômeno da vi olên cia em duas es colas: es tu do decaso. Por to Alegre, 104p. Dis serta ção (Mestrado) - Faculdade de Educação da Universidade Federal do Rio Grande do Sul.

PAIM COSTA, Giseli. Arepercus sãoda violência social nocotidiano es colar. Porto Alegre; 2000. Dis serta ção (Mes tra do)UFRGS.

PAIM, Iracema de Macedo. As representações e a prática da violência no espaço escolar. Niterói; 1997. Dissertação (Mestrado) - Universidade Federal Fluminense.

PERALVA, Ange lina. Escola eviolên cia nas periferias urbanas francesas. ContemporaneidadeeEducação. Rio de a a neiro: IEC, Ano II, número 2, 1997. 
Democracia, violência e modernização por baixo. Revista Lua Nova, s.d.

. Violência e democracia. 0 paradoxo brasileiro. Rio de J aneiro: Paz e Terra, 2000.

PINTO, TeresinhaCris tinaRekis. A ques tão da depreda ção es colar. In: Conferência BrasileiradeEducação, Anais 6. São Paulo: Papirus, 1992.

RODRIGUES, AnitaSchu mann. Aqui não há violência:Aes colasilenciada(Umestudoetno gráfico). Rio de Janeiro; 1994. 91p. Dissertação (Mestrado ) - Pontifícia Universidade Católica do Rio de J aneiro.

SANTOS,J oséVicen te Ta va res (org). A pala vraeo ges to em pa reda dos: a vio lên cia na es cola. Por to Ale gre: PMPA/SMED, 1999.

SARMENTO, Walney M. Educa çãoformal:um desencontroEscola-Comunidade. TecnologiaEducacional , v. 16, n. 75/76, 1987.

SOUTO, J ane. Os outros lados do funk carioca. In: VIANNA, H (org). Galeras cariocas. Rio de Janeiro: Editora da UFR, 1997.

SPOSITO, MariliaPontes. “Violenciacolectiva, jóvenes yeducación”. México: RevistaMexicanadeSociologia, n. 3., 1994.

A sociabilidade juvenil e a rua: novos conflitos e ação coletiva na cidade. Tempo Social. São Paulo: Departamento de Sociologia, FFLCH/USP, v.5, n. 1-2, 1993, editado em 1994a.

. A instituição escolar e a violência. Cadernos de Pesquisa. Fundação Carlos Chagas, 104, 1998.

Paulo: 1999.

(coord.). J uventude e Escolarização: uma análise da produção do conhecimento. Relatório de pesquisa. São (coord). J uventude: estado do conhecimento. Relatório de pesquisa. INEP, 2000.

VENTURI, Gustavo e ABRAM0, Helena. J uventude, política e cultura. Teoria e Debate, São Paulo, n. 45, 2000.

VELHO, Gilberto e ALVITO, Marcos. Cidadania e violência. Rio de J aneiro: UERJ/FGV, 1996.

VIANNA, Hermano. 0 mundo funk carioca. Rio de J aneiro: UFRJ , 1988.

WAISELFISZ, Júlio J . J uventude, violência e cidadania. Os jovens de Brasília. São Paulo: Cortez Editora, 1998.

ZALUAR, Alba. (org.) Violência e Educação. São Paulo, Cortez, 1992.

ZALUAR, Alba. A máquina ea revol ta. As organizações po pulares eo significado da pobreza. SãoPaulo: Brasiliense, 1985. Condomínio do diabo. Rio de J aneiro: Revan/UFRJ, 1994.

Violência e crime. In: MICELI, Sergio (org). 0 que ler na Ciência Social brasileira (1970-1995). vol 1, Antropologia. São Paulo: Sumaré, 1999.

ZALUAR, A e LEAL, Ma ria Cris tina. Gêne ro eedu ca ção pú bli ca: uma com pa ra ção en tre o CIEP e a Esco la Co mum. Revista Brasileira de Estudos Pedagógicos. Brasilia: INEP, v. 78, núm. 188/189/190, 1997.

Recebido em 28.08.01

Aprovado em 04.09.01

Marilia Pontes Sposito é professora associada do Departamento de Filosofia da Educação e Ciências de Educação da Faculdade de Educação da USP, doutora em Educação e membro da diretoria de Ação Educativa. 